\title{
Comparison of two recombinant hepatitis B vaccines and their interchangeability in Argentine infants
}

\author{
Miguel Tregnaghi, ${ }^{1}$ José Ussher, ${ }^{1}$ Ana María Baudagna, ${ }^{1}$ \\ Miriam Calvari, ${ }^{1}$ and Gabriela Graña ${ }^{1}$
}

ABSTRACT Objective. To compare two pediatric recombinant hepatitis B vaccines-the Engerix-B reference vaccine and the Euvax-B vaccine-in terms of immunogenicity and reactogenicity, and also to investigate their interchangeability, that is, whether a three-dose hepatitis B vaccination schedule begun with a first dose of Engerix-B could be completed with two doses of Euvax-B. Methods. This study was conducted in the city of Córdoba, Argentina, from March 1999 through February 2000. Three groups of Argentine newborns (100 per group) were vaccinated at 0,1 , and 6 months of age with hepatitis B vaccine: group $A$, three doses of Euvax-B; group $B$, three doses of Engerix- $B$; and group $C$, one dose of Engerix- $B$ followed by two doses of Euvax-B. Reactogenicity was evaluated based on parental reporting of any solicited local or systemic event occurring during the 7-day period following vaccination. Whether Euvax-B and Engerix- $B$ were clinically identical was assessed in terms of the seroprotection rates (antibodies to hepatitis $B$ surface antigen (anti-HBs $A g$ ) $\geq 10$ milli-international units per $m L$ (mIU/mL) 2 months after the third vaccination).

Results. Reactogenicity was low in all three groups. Five months after the second dose (that is, immediately prior to the third vaccination), seroprotection rates were $95.9 \%, 94.7 \%$, and $90.2 \%$ for groups $A, B$, and $C$, respectively. Two months after the third dose all subjects were seroprotected, with geometric mean concentrations of anti-HBsAg of 2 468.1, 1 714.8, and $2075.3 \mathrm{mIU} / \mathrm{mL}$ for groups $A, B$, and $C$, respectively.

Conclusions. Both of the recombinant hepatitis B vaccines that we studied were well tolerated and highly immunogenic. Euvax-B was clinically identical (not inferior) to the Engerix$B$ reference vaccine, and either vaccine could be used to achieve the World Health Organization goal of immunizing all infants against hepatitis B. Further, Euvax-B can be safely used in infants given an initial dose of either Euvax-B or Engerix-B.

Key words Hepatitis B, vaccines, immunization programs, infant.

One aim of the Expanded Program on Immunization of the World Health

\footnotetext{
1 Hospital Infantil Municipal de Córdoba, Centro de Desarrollo de Proyectos Avanzados, Córdoba, Córdoba, Argentina. Send correspondence to: Miguel Tregnaghi, Centro de Desarrollo de Proyectos Avanzados, Hospital Infantil Municipal de Córdoba, Lavalleja 3050, Barrio Alta, Córdoba $5000-$ Córdoba, Argentina; telephone: 54-351-425-1800; fax: 54-351-425-6373; e-mail: miguelt@millicom. com.ar
}

Organization (WHO) has been the immunization of all infants against hepatitis B (1), and, according to the Global Alliance for Vaccines and Immunization, all countries should introduce hepatitis B vaccine into their national immunization programs by 2007 (2). Indeed, hepatitis B infection is one of the leading causes of vaccinepreventable infant morbidity around the world (2), and universal childhood immunization has been proposed to combat the spread of this virus (3). To achieve universal immunization of infants the WHO has recommended administering three doses of recombinant hepatitis $B$ vaccine in the first year of life. One dose should be given at birth in areas of medium endemicity (carriage rate of $2 \%$ to $8 \%$ ) or 
of high endemicity (carriage rate $>8 \%)$. In countries with low endemicity $(<2 \%)$ the recommendation is for three doses of vaccine by 6 months of age.

Argentina has a low endemicity of hepatitis B infection. There are currently two recombinant hepatitis $B$ vaccines that are available for infant vaccination in the country. One is the established Engerix-B vaccine, which is produced by GlaxoSmithKline Biologicals (Rixensart, Belgium), and the other is the more recently introduced Euvax-B vaccine, which is manufactured by Lucky Goldstar (Seoul, Korea) and marketed in Argentina as Hepativax by Aventis Pasteur.

This study was performed to compare the immunogenicity and reactogenicity of these two vaccines when administered to Argentine infants in a three-dose schedule at 0,1 , and 6 months of age. Engerix-B was considered the reference vaccine in this study. Another purpose of this research was to determine if a hepatitis B vaccination schedule initiated with Engerix-B could be completed with the other vaccine, Euvax-B. In many cases the vaccines administered in the hospital soon after birth will be different from those available from health clinics at well-baby visits. In addition, in Argentina and elsewhere, governments can change vaccine suppliers from year to year. In general, the information available concerning the interchangeability of hepatitis vaccines is limited. For those various reasons we included in our study a group to test whether changing vaccines during the primary series (that is, giving Engerix$\mathrm{B}$ as the first dose, followed by two doses of Euvax-B) would affect the protection provided.

\section{METHODS}

This study was a comparative, randomized, controlled, observer-blinded trial conducted in the city of Córdoba, Argentina, from March 1999 through February 2000. The same medical team conducted the trial in one principal center, the Center for the Develop- ment of Advanced Projects (Centro de Desarrollo de Proyectos Avanzados) of the Córdoba Municipal Children's Hospital (Hospital Infantil Municipal de Córdoba), and in seven satellite health care centers in the city of Córdoba. The study protocol was approved by the Children's Hospital ethical committee, the Ministry of Health, and the National Independent Ethics Committee. The study was conducted in accordance with the Declaration of Helsinki and the International Conference on Harmonization's Good Clinical Practice standard applicable at study initiation. For each child one of the parents or a guardian gave written informed consent prior to study entry. In addition, in line with local regulations, an independent witness also gave written informed consent, in order to ensure that there was no undue influence for subjects to participate in the trial.

\section{Subjects}

Intended subjects were healthy, fullterm infants at 0 months of age. Infants were excluded if they met any of the following criteria: allergy to one of the vaccine components, acute febrile illness (oral temperature $\geq 37.5^{\circ} \mathrm{C}$ ), existing chronic illness (heart disease, respiratory disease, etc.), inclusion in another clinical trial, previous vaccination against hepatitis $B$, immunocompromised (including HIV infection), or receiving immunosuppressive therapy. Subjects were not to receive any other vaccinations (except for BCG) within 7 days of the hepatitis B vaccinations. Enrolled subjects were randomly assigned to one of the three study groups according to a randomization list generated using SAS computer software (SAS Institute Inc., Cary, North Carolina, United States of America).

\section{Vaccines}

Both hepatitis B vaccines investigated in this study contain $10 \mu \mathrm{g}$ of recombinant hepatitis B surface antigen
(HBsAg) per 0.5-mL dose, with aluminum hydroxide as adjuvant. All infants received three doses of vaccine: the first one in the first month of life (month 0 ), the second dose 1 month later (month 1), and the third dose 5 months after that (month 6). Infants received three doses of Euvax-B (group A), three doses of Engerix-B (group B), or a first dose of Engerix-B followed by two doses of Euvax-B (group C). An observer-blinded study design was used so that, when they evaluated local and systemic reactions to the vaccines, the researchers would not be aware of which children had received which vaccine or vaccines. A study nurse gave each vaccine dose by intramuscular injection in the anterolateral thigh.

\section{Immunogenicity}

Blood samples (2 mL) were collected at three points: (1) immediately prior to the first vaccinations (month 0), (2) immediately prior to the third vaccinations (month 6), and (3) 2 months after the final vaccination (month 8). Sera were prepared immediately and stored at $-20{ }^{\circ} \mathrm{C}$ until and during transport to the Aventis Pasteur Laboratory, Val de Reuil, France, where serum concentrations of antibodies to hepatitis B surface antigen (antiHBsAg) were measured by radioimmunoassay using the AUSAB commercial test kit (Abbott Laboratories, Abbott Park, Illinois, United States). The assay was calibrated with a WHO standard reference, and concentrations were expressed in milli-international units per $\mathrm{mL}(\mathrm{mIU} / \mathrm{mL})$, with a cut-off value of $2 \mathrm{mIU} / \mathrm{mL}$. The response was assessed for each of the three groups as geometric mean concentrations (GMCs) of anti-HBsAg (with 95\% confidence intervals) and as seroprotection rates (percentage with $\geq 10 \mathrm{mIU} / \mathrm{mL}$ ) at month 6 and at month 8 . We also determined the proportions of infants who were initially seronegative for antibodies to hepatitis B surface-antigen who seroconverted (presented with anti-HBsAg $\geq 2 \mathrm{mIU} /$ $\mathrm{mL}$ after vaccination). 


\section{Safety and reactogenicity}

After vaccination, each subject was observed for $30 \mathrm{~min}$ for the appearance of any immediate reactions. At each vaccination visit, parents were provided with a diary card on which to record the date of onset, date of resolution, and severity of any solicited local or systemic event occurring during the 7-day period following vaccination. The local reaction assessment involved assessment of the vaccination site for pain (absent or present), erythema, hematoma, edema, and induration (measured using a supplied ruler). Systemic reaction assessment involved daily axillary temperature readings (measured with a digital thermometer), with fever being defined as an axillary temperature $\geq 37.5^{\circ} \mathrm{C}$. Any other systemic complaints, such as irritability, insomnia, and vomiting, were recorded. Serious adverse events were to be reported immediately whenever they occurred during the course of the study. Diary cards were returned to the investigators at the subsequent study visit, and an investigator who interviewed the parents confirmed the interim medical histories and the relationship of recorded symptoms to the vaccination.

\section{Statistical methods}

The primary objective of the study was to compare the immunogenicity of the two vaccines in terms of postvaccination seroprotection rates 2 months after the third vaccination (that is, at month 8). Secondary objectives were the assessment of seroconversion and seroprotection rates and GMCs at month 6 (immediately before the third dose) and seroconversion and GMCs at month 8. The null hypothesis was that the difference in post-dose-3 seroprotection rates was greater than or equal to the clinically acceptable difference. The reference seroprotection rate for Engerix-B was taken as 95\% (4), and the clinically relevant difference was set at $10 \%$. Anticipating that there would be no difference in true seroprotection rates between test groups and a type I er-

TABLE 1. Demographic characteristics of the enrolled subjects in the three study groups, including serostatus with respect to antibodies to hepatitis B surface antigen (anti-HBsAg) before any hepatitis B vaccination, Córdoba, Córdoba, Argentina, 1999-2000

\begin{tabular}{|c|c|c|c|}
\hline \multirow[b]{2}{*}{ Characteristic } & \multicolumn{3}{|c|}{ Study group ${ }^{a}$} \\
\hline & A & $B$ & $\mathrm{C}$ \\
\hline Number of subjects enrolled & 100 & 100 & 100 \\
\hline \multicolumn{4}{|l|}{ Gender } \\
\hline Male & 59 & 50 & 46 \\
\hline Female & 41 & 50 & 54 \\
\hline \multicolumn{4}{|l|}{ Age (days) } \\
\hline Mean & 15.4 & 17.2 & 16.6 \\
\hline Standard deviation & 6.6 & 6.8 & 6.7 \\
\hline \multicolumn{4}{|l|}{ Anti-HBsAg serostatus before vaccination } \\
\hline Unknown & 3 & 0 & 2 \\
\hline$\geq 2$ milli-international units $/ \mathrm{mL}$ (mlU/mL) & 4 & 2 & 7 \\
\hline$\geq 10 \mathrm{mIU} / \mathrm{mL}$ & 1 & 1 & 1 \\
\hline$\geq 100 \mathrm{mlU} / \mathrm{mL}$ & 1 & 0 & 0 \\
\hline \multicolumn{4}{|l|}{ Excluded from final analysis } \\
\hline Withdrawn by parents & 2 & 3 & 3 \\
\hline Lost to follow-up & 1 & 1 & $2^{b}$ \\
\hline Completed & 97 & 96 & 95 \\
\hline
\end{tabular}

aroup A = $3 \times$ Euvax-B; Group B = $3 \times$ Engerix-B; Group C = $1 \times$ Engerix-B and $2 \times$ Euvax-B.

${ }^{b}$ Includes one case of sudden infant death syndrome.

ror probability $(\alpha)$ of $5 \%$, the required sample size was calculated to be 82 subjects per group. In anticipation of a $15 \%$ dropout rate and an initial 3\% seropositivity rate, 100 subjects per group were enrolled. The analysis of reactogenicity was descriptive.

\section{RESULTS}

\section{Demographics}

A total of 300 subjects (155 boys and 145 girls), aged from 4 to 31 days, were enrolled in the three study groups. There were no significant differences in demographics among the three groups (Table 1). All the subjects received at least one vaccination, and 288 completed the study.

At visit 4 (month 8 ) the 12 subjects who did not have a blood sample drawn were composed of: 8 who were withdrawn by their parents ( 2 from group A, 3 from group B, and 3 from group $\mathrm{C}$ ); 3 subjects who were lost to follow-up, one in each of the three groups; and one case of sudden infant death syndrome. That case of sudden infant death syndrome, in group C, occurred 17 days after the second dose. That infant had been previously treated for bronchiolitis with salbutamol and betamethasone. The autopsy report concluded that the infant died due to cardiorespiratory failure; no other findings were reported. The investigator assessed this serious adverse event and concluded it was not related to the vaccination.

Earlier, at month 6 (visit 3), a total of 17 subjects either did not provide blood samples or the blood samples that were taken were not assayable because the volume of serum was inadequate.

\section{Immunogenicity}

At month 6, after two doses of vaccine, $95.9 \%$ (93 of 97 subjects), $94.7 \%$ (89 of 94 subjects), and $90.2 \%$ (83 of 92 subjects) in groups A, B, and C, respectively, had seroprotective antibody concentrations (Table 2). These proportions increased to $100 \%$ in all three groups 2 months after the third vaccination (month 8). That is, three doses of Euvax-B or two doses of Euvax-B after an initial dose of Engerix-B were not inferior to three doses of the Engerix-B reference vaccine. This is supported by the evolution of the GMCs in 
TABLE 2. Seroprotection and seroconversion rates and geometric mean concentration (GMC) of antibodies to hepatitis B surface antigen (anti-HBsAg) of the three study groups after two doses (month 6 ) and three doses (month 8 ) of the respective hepatitis $B$ vaccines, Córdoba, Córdoba, Argentina, 1999-2000

\begin{tabular}{|c|c|c|c|}
\hline & \multicolumn{3}{|c|}{ Study group ${ }^{a}$} \\
\hline & A & B & C \\
\hline \multicolumn{4}{|l|}{ No. of subjects } \\
\hline Month 6 & 97 & 94 & 92 \\
\hline Month 8 & 97 & 96 & 95 \\
\hline \multicolumn{4}{|c|}{ Seroprotection rate $(\%)^{b}$} \\
\hline Month 6 & 95.9 & 94.7 & 90.2 \\
\hline Month 8 & 100 & 100 & 100 \\
\hline \multicolumn{4}{|c|}{ Seroconversion rate $(\%)^{c}$} \\
\hline Month 6 & 100 & 100 & 97.6 \\
\hline Month 8 & 100 & 100 & 100 \\
\hline \multicolumn{4}{|l|}{$\mathrm{GMC}(\mathrm{mlU} / \mathrm{mL})^{\mathrm{d}}$} \\
\hline Month 6 GMC & 117.5 & 127.2 & 113.9 \\
\hline Month 6 95\% Cl & 86.9 to 158.8 & 94.3 to 171.4 & 81.4 to 159.4 \\
\hline Month 8 GMC & 2468.1 & 1714.8 & 2075.3 \\
\hline Month $895 \% \mathrm{Cl}$ & 1964.3 to 3101.0 & 1342.0 to 2191.2 & 1498.2 to 2874.7 \\
\hline
\end{tabular}

a Group A = $3 \times$ Euvax-B; Group B $=3 \times$ Engerix-B; Group $\mathrm{C}=1 \times$ Engerix-B and $2 \times$ Euvax-B.

${ }^{\mathrm{b}}$ Seroprotection rate $=$ proportion of subjects with anti-HBsAg $\geq 10$ milli-international units $/ \mathrm{mL}$.

c Seroconversion rate $=$ percent of initially seronegative subjects seropositive ( $\geq 2$ milli-international units $/ \mathrm{mL})$ after vaccination.

${ }^{d}$ Geometric mean concentration (GMC) of anti-HBsAg (milli-international units per $\mathrm{mL}$ ), with $95 \%$ confidence interval (Cl). the three groups (Table 2). The final GMCs were $2468.1,1714.8$, and 2075.3 $\mathrm{mIU} / \mathrm{mL}$, for groups $\mathrm{A}, \mathrm{B}$, and $\mathrm{C}$, respectively. The overlapping $95 \%$ confidence intervals for the GMCs show that the differences in values among the three groups were not statistically significant.

\section{Reactogenicity}

Immediate reactions (within $30 \mathrm{~min}$ of injection) observed after any injection occurred with similar frequencies in all three study groups. A total of 18,28 , and 25 subjects from groups $\mathrm{A}, \mathrm{B}$, and $\mathrm{C}$, respectively, experienced
TABLE 3. Percentages of subjects experiencing at least one solicited local or systemic reaction within 7 days of any of the three injections with the two studied recombinant hepatitis B vaccines, Córdoba, Córdoba, Argentina, 1999-2000

\begin{tabular}{lrrr}
\hline & \multicolumn{3}{c}{ Study group ${ }^{\mathrm{a}}$} \\
\cline { 2 - 4 } & $\mathrm{A}$ & $\mathrm{B}$ & $\mathrm{C}$ \\
\hline Local reactions (\% of subjects) & & & \\
Any & 33.0 & 31.3 & 39.8 \\
$\quad$ Pain & 20.0 & 14.1 & 24.5 \\
$\quad$ Erythema & 19.0 & 20.2 & 24.5 \\
Hematoma & 3.0 & 4.0 & 7.1 \\
Edema & 9.0 & 8.1 & 9.2 \\
Induration & 19.0 & 14.1 & 18.4 \\
Systemic reactions (\% of subjects) & & & \\
Any & 61.0 & 56.6 & 66.3 \\
$\quad$ Any related event & 53.0 & 45.5 & 56.1 \\
$\quad$ Fever & 22.0 & 20.2 & 23.5 \\
$\quad$ Irritability & 45.0 & 26.3 & 38.8 \\
$\quad$ Drowsiness & 14.0 & 16.2 & 28.6 \\
$\quad$ Unusual crying & 22.0 & 14.1 & 18.4 \\
\hline
\end{tabular}

\footnotetext{
${ }^{a}$ Group $A=3 \times$ Euvax-B; Group $B=3 \times$ Engerix-B; Group $C=1 \times$ Engerix-B and $2 \times$ Euvax-B.
}

${ }^{b}$ Fever $=$ axillary temperature $\geq 37.5^{\circ} \mathrm{C}$. at least one immediate reaction during the study. These reactions were all transient and mild in intensity, consisting mainly of erythema or induration around the injection site.

Local and systemic safety analysis was performed on 297 subjects within 7 days of the first injection, on 291 subjects for the second injection, and on 288 subjects for the third injection. The two vaccines studied presented similar reactogenicity profiles with regard to the frequency of solicited events reported within 7 days after each injection in all three groups (Table 3 ). The reactions were mostly of mild to moderate intensity, and the majority occurred and resolved within the observation period of 7 days after vaccination.

There was no consistent trend of more local reactions with consecutive injections. In group A the percentages of doses 1, 2, and 3 associated with local reactions were $12 \%, 12.2 \%$, and $24.7 \%$, respectively; in group B they were $16.2 \%, 10.3 \%$, and $18.8 \%$; and in group C they were $21.4 \%, 22.9 \%$, and $16.8 \%$.

There were only five reports of local reactions that were severe $(>5 \mathrm{~cm}$ in diameter): three cases of erythema in group $C$ (two after the Engerix-B dose and one after the first dose of Euvax-B) and two cases of edema, both occurring after the first dose of Engerix- $\mathrm{B}$ (one each in groups B and C).

A systemic event considered to have a possible, probable, or definite relationship to vaccination was classified as "related." About half of all the subjects in each group were reported to have had a "related" systemic reaction (Table 3). The most common systemic reaction was irritability, followed by fever. Most cases of fever were mild $\left(37.5^{\circ} \mathrm{C}\right.$ to $\left.38.5^{\circ} \mathrm{C}\right)$, but there were two cases of high fever, one in group A $\left(40.1{ }^{\circ} \mathrm{C} 5\right.$ days after the third vaccination) and one in group $\mathrm{C}\left(39.8^{\circ} \mathrm{C}\right.$ on the day of the third dose). All fever episodes were resolved without sequelae within 7 days. Most other systemic reactions occurred within the first 2 days after vaccination, and they lasted no more than 3 days.

In addition to the one fatality described above, there were 32 other seri- 
ous adverse events (SAEs) reported in 28 subjects during this study (11 subjects in group A, 6 in group B, and 11 in group $\mathrm{C}$ ). None of the SAEs was considered to be related to the vaccinations. All 32 SAEs resolved spontaneously.

\section{DISCUSSION}

Hepatitis B infection is a serious global public health problem, affecting many millions of people every year. Infection can lead to serious morbidity, sometimes irreversible liver damage, and even death. Many patients who recover from the acute stages of the infection become chronic carriers who may be asymptomatic or who may develop chronic hepatitis, which in turn may lead to hepatocarcinoma (5). Infection in children is associated with an increase in chronic carriage (6).

Two major global childhood vaccination initiatives, the Expanded Program on Immunization and the Global Alliance for Vaccines and Immunization (GAVI), recommend vaccination of all infants against hepatitis B $(1,2)$, which could prevent 900000 cases of hepatitis B annually (2). However, as recently noted by the GAVI, there is an increasing demand for hepatitis B vaccine and a risk that this demand could not be satisfied by existing manufacturers (7). It is therefore essential that new vaccines be available for inclusion in national immunization schedules.

Several recombinant hepatitis B vaccines are available from different manufacturers, all based on the $S$ protein component of the hepatitis B surface antigen. Our study was intended to determine whether the recently licensed pediatric formulation of Euvax-B offers the same protection against hepatitis $B$ as the established Engerix-B vaccine when administered to newborns at 0,1 , and 6 months. The Advisory Committee on Immunization Practices (ACIP) of the United States has suggested that the similar basis of hepatitis B vaccines means that a mixed regimen, with different vaccines for the three doses, would not diminish the protection provided by the complete series (3). Since the vaccine administered in a maternity hospital may be different from what is provided by external well-baby clinics, we also examined the effects of giving two doses of Euvax-B after an initial dose of Engerix-B in order to assess the ACIP statement.

In our study three doses of hepatitis $B$ vaccine surpassed the anticipated 95\% protection rate, with all subjects achieving serum concentrations of anti-HBsAg $\geq 10 \mathrm{mIU} / \mathrm{mL}$. As the three groups were identical in this respect, it showed that both the three-dose schedule of Euvax-B and the mixed regimen of Engerix-B followed by two doses of Euvax-B were not clinically inferior to three doses of the reference vaccine, Engerix-B. Indeed, the final GMCs achieved with the two "test" schedules were somewhat, but not significantly, higher than that achieved by Engerix-B. The high GMCs in all three groups in our study (2 468.1, 1714.8 , and $2075.3 \mathrm{mIU} / \mathrm{mL}$ ) are similar to or higher than those achieved in infants in the United States 1 month after three doses of Engerix-B (1 $914.8 \mathrm{mIU} / \mathrm{mL}$ ) or Merck's Recombivax vaccine $(514.8 \mathrm{mIU} / \mathrm{mL})$ given at 2,4 , and 6 months of age (8). We used the schedule of 0,1 , and 6 months in our study because it has been shown previously that increasing the interval between the second and third doses gives higher concentrations of anti-HBsAg (9). Similar results have been reported for the $10 \mu \mathrm{g}$ dose of HBsAg in other pediatric studies (10).

These high antibody concentrations found after the administration of three hepatitis B vaccine doses are indicative that protection would be provided for several years. In a previous study (11) a GMC of $3341 \mathrm{mIU} / \mathrm{mL}$ was found one month after completion of an immunization schedule of $0,1,2$, and 12 months. Among the neonates in the group who were not boosted at month 60 but were followed up to month 96 the seropositivity was still $95.5 \%$. In addition, infants vaccinated on a schedule of 0,1 , and 6 months had a seroprotection rate of $98.2 \%$ at 3 months after the third dose, with a GMC of 507 $\mathrm{mIU} / \mathrm{mL}$. At 5 years of age, $87.5 \%$ of this group were still seroprotected, and all subjects responded anamnestically to a booster dose, suggesting that immunologic memory had been induced. Another study (12) demonstrated immunologic memory in children 7 years after primary immunization. The high GMC levels provided by the schedule that we used $(0,1,6$ months) would be expected to provide protection until at least adolescence.

In agreement with previous reports, all three of the vaccine series in our Argentina study (only Engerix-B, only Euvax-B, and mixed) were well tolerated. There were no serious adverse events associated with the vaccinations except for two cases of high fever, which resolved rapidly without sequelae. The vast majority of local and systemic reactions were mild and transient, and they were associated equally with the Euvax-B and Engerix$B$ vaccines, in both the single-vaccine regimens and the mixed regimen.

This study demonstrates that the pediatric formulations of the two recombinant hepatitis B vaccines studied are highly immunogenic in infants, are well tolerated, and can be expected to provide protection against hepatitis $B$ infection in over $95 \%$ of the vaccinees for many years. Euvax-B, recently licensed in Argentina, did not display any clinical inferiority to the Engerix-B reference vaccine in terms of immunogenicity or reactogenicity. Indeed, Euvax-B could be used with confidence to provide the second and third doses for infants who received a primary vaccination in a hospital, irrespective of which vaccine had been used for the primary dose, without compromising the protection afforded.

Acknowledgments. This study was supported financially by a grant from Aventis Pasteur International (AvPI), Lyon, France.

Note on conflict of interest. The Pan American Health Organization (PAHO) has purchased vaccines from Aventis Pasteur, and PAHO has also received contributions from the company. While the Revista Panamericana de Salud Pública/Pan American Journal of 
Public Health is affiliated with PAHO, the Revista/Journal is an independent scientific publication whose articles do not necessarily reflect the opinions or official positions of $\mathrm{PAHO}$ on specific issues. The mention of particular companies or of certain manufacturers' products in the Revista/Journal does not imply that they are endorsed or recommended by $\mathrm{PAHO}$ in preference to other ones of a similar nature. As with all other research articles published in the Revista/Journal, this article went through the regular process of peer review by outside experts.

\section{REFERENCES}

1. Expanded Progamme on Immunization. Global Advisory Group - Part I. Wkly Epidemiol Rec 1992:67:11-15.

2. World Health Organization. Global Alliance for Vaccines and Immunization (GAVI). Geneva: WHO; 2001. (Fact Sheet No. 169).

3. Hepatitis B virus: a comprehensive strategy for eliminating transmission in the United States through universal childhood vaccination: recommendations of the Immunization Practices Advisory Committee (ACIP). MMWR Recomm Rep 1991;40(RR-13):1-25.

4. Szmuness W, Stevens CE, Harley EJ, Zang EA, OlezKo WR, William DC, et al. Hepatitis $B$ vaccine: demonstration of efficacy in a controlled trial in a high-risk population in the United States. N Engl J Med 1980;303:833-841.

5. Lee WM. Hepatitis B virus infection. N Engl J Med 1997;337:1733-1745.
6. Edmunds WJ, Medley GF, Nokes DJ, Hall A, Whittle $\mathrm{H}$. The influence of age on the development of the hepatitis B carrier state. Proc $\mathrm{R}$ Soc Lond B Biol Sci 1993;253:197-201.

7. Global Alliance for Vaccines and Immunization. A smarter way to buy. Immunization Focus, November 2000: 8-9.

8. Greenberg DP, Vadheim CM, Wong VK, Marcy SM, Partridge S, Greene T, et al. Comparative safety and immunogenicity of two recombinant hepatitis $B$ vaccines given to infants at two, four and six months of age. Pediatr Infect Dis J 1996;15:590-596.

9. Jilg W, Schmidt M, Deinhardt F. Vaccination against hepatitis B: comparison of three different vaccination schedules. J Infect Dis 1989; 160:766-769.

10. Adkins JC, Wagstaff AJ. Recombinant hepatitis $B$ vaccine: a review of its immunogenicity and protective efficacy against hepatitis B. Biodrugs 1998;10:137-158.

11. Poovorawan Y, Sanpavat S, Chumdermpadetsuk A, Safary A. Long-term hepatitis B vaccine in infants born to hepatitis $B$ e antigen positive mothers. Arch Dis Child 1997;77: F47-F51.

12. Gonzalez ML, Gonzalez JB, Salva F, Lardinois R. A 7-year follow-up of newborns vaccinated against hepatitis B. Vaccine 1993;11:10331036.

Manuscript received 18 November 2002. Revised version accepted for publication on 13 May 2003.

RESUMEN Objetivo. Comparar dos vacunas pediátricas recombinantes contra la hepatitis B -Euvax-B y la vacuna de referencia Engerix-B - en cuanto a su inmunogenicidad y reactogenicidad, e investigar su intercambiabilidad, es decir, si el esquema de vacunación contra la hepatitis B de tres dosis comenzado con una primera dosis de Engerix-B puede completarse con dos dosis de Euvax-B.

\section{Comparación de dos vacunas recombinantes contra la hepatitis B y su intercambiabilidad en lactantes argentinos}

Métodos. Este estudio se llevó a cabo en la ciudad de Córdoba, Argentina, entre marzo de 1999 y febrero de 2000. Se vacunó contra la hepatitis B a tres grupos de 100 lactantes argentinos a los 0, 1 y 6 meses de edad. El grupo A recibió tres dosis de EuvaxB; el grupo B, tres dosis de Engerix-B; y el grupo C, una dosis de Engerix-B seguida de dos dosis de Euvax-B. Para evaluar la reactogenicidad se utilizó la información brindada por los padres acerca de determinados fenómenos locales o sistémicos solicitados por los investigadores que hubieran ocurrido durante los siete días posteriores a la vacunación. Para establecer si eran idénticas clínicamente las vacunas Euvax-B y EngerixB se utilizaron las tasas de seroprotección - es decir, títulos de anticuerpos contra el antígeno de superficie de hepatitis B (anti-HBsAg) $\geq 10$ miliunidades internacionales por mililitro (mUI/mL) - alcanzados dos meses después de la tercera dosis.

Resultados. La reactogenicidad fue baja en los tres grupos de estudio. A los 5 meses de la segunda dosis (es decir, inmediatamente antes de la tercera dosis), las tasas de seroprotección fueron $95,9 \%, 94,7 \%$ y 90,2\% en los grupos A, B y C, respectivamente. Dos meses después de la tercera dosis, todos los lactantes se encontraban protegidos, con concentraciones medias geométricas de anti-HBsAg de $2468,1 \mathrm{mUI} / \mathrm{mL}$ en el grupo A, de $1714,8 \mathrm{mUI} / \mathrm{mL}$ en el grupo B y de 2 075,3 mUI/mL en el grupo C.

Conclusiones. Las dos vacunas recombinantes contra la hepatitis B estudiadas fueron bien toleradas y altamente inmunogénicas. La vacuna Euvax-B fue clínicamente idéntica (no inferior) a la vacuna de referencia Engerix-B y cualquiera de ellas puede utilizarse para alcanzar la meta propuesta por la Organización Mundial de la Salud de inmunizar a todos los recién nacidos contra la hepatitis B. Además, puede emplearse con seguridad la vacuna Euvax-B en lactantes que recibieron una primera dosis con Euvax-B o Engerix-B. 